\title{
Profiling Italian cat and dog owners' perception of pet food quality in purchasing habits
}

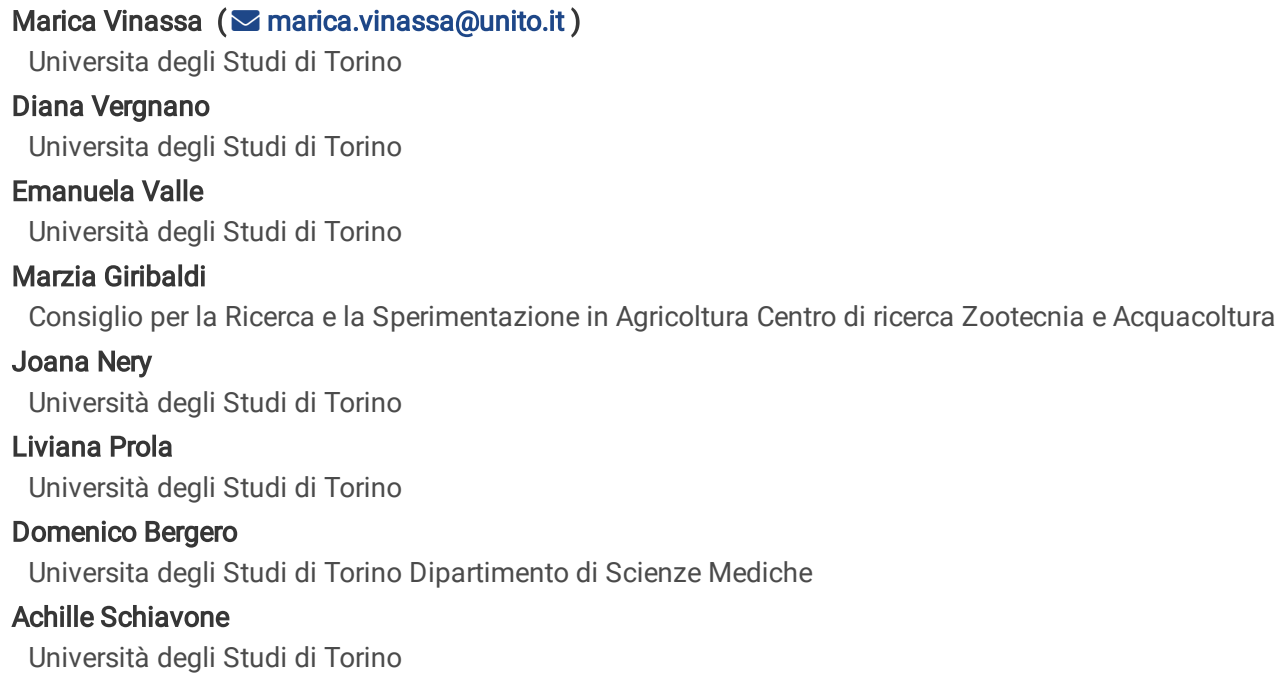




\section{Abstract}

Background. In these last years there is a growing sensibility of public opinion towards pet animal, that involves also an in increasing attention on their nutrition, seen as a way to guarantee welfare. However, it is difficult for the consumer to understand the quality of a product because label information is not always clear to the consumer. The aim of the study is to identify through a survey the pet food characteristics that are seen as quality indicators for pet owners.

Results. In total 935 surveys were collected. Descriptive statistic showed a higher percentage of female owners (61.8\%) among pet food buyers. Participants were divided almost equally between dogs owners (39.4\%), cats owners (30.8\%) or both dogs and cats owners (29.8\%). A quarter of owners (25.5\%) asked for advice to veterinary on which pet food to buy and about a third (30.4\%) trusts in web sites of major brands, giving both of them an higher responsibility in providing information to the buyer. "Contain natural ingredients" was the characteristic with the highest score (4.3 on 5), confirming nowadays market trends. Correspondence analysis for age showed that older owners ( $>65 \mathrm{y}$ ) put more attention on costs, with low emphasis on food appearance, animal satisfaction and fecal quality. Younger owners ( $<35 \mathrm{y}$ ) put more attention on positive influence on animal feces, high percentage of protein, presence of recyclable packaging and less attention at food appearance, smell and animal satisfaction. Appearance, smell, higher cost and some label indication (protein content, presence of fresh meat, low grains content) are relevant for consumers buying wet pet food. Some differences are showed between owners of different animal species. Cat owners give more importance to appearance, smell and production site, dog owners focus on protein content, presence of meat as a first ingredient and higher cost.

Conclusions. Italian pet food buyers, considered as the most important quality indicators the presence of natural ingredients, while the least important was the high price. Information from this survey can help the pet food companies to identify the factors that influence the perceived quality of the products by dog and cat owners.

\section{Background}

In Italy around 39\% of family own at least a cat or a dog [1] and in recent years, dog and cat food market had a positive trend [1]. Furthermore, sensibility of consumers towards pet care is growing [1] and nutrition is seen as a way to guarantee welfare. Pet diet is inevitably determined by pet owners that have different and specific expectations that pet food should fulfill. Nowadays, consumers are more aware about the quality and the ingredients used in their pet's feed Furthermore, their choice can be influenced by different social and cultural factors, the same that rule the differences within individuals on people's eating behaviour. Wholesomeness, safety of feed ingredients, perception of nutritional value are major features that influence choice, together with their ideas about industrial pet food and their sources of information on pet nutrition[2]. In fact, buyers have access to numerous sources of information about pet nutrition (veterinarians, internet, trainers, pet shop employees, books of pet nutrition, pet nutrition company's website, other pet owners...), even if they are not always accurate [3]. Some feed's features are perceived as positive and linked to health benefits, such as "organic" or "grain free", otherwise other ingredients (i.e. grain) are now often seen as negative because of an idea of a potentially harmful effect [4]. Pet food producers take into account this information, promoting their products with claims as "free range/organic/natural" [5,6]. Commercial complete foods are cited as a contributing factor for longer, healthier life spans in pets [7] and their use is widespread in developed countries and in Italy too [1], even if there is an increasing interest regarding alternative feeding strategies [811].

This growing attention affect consumer behaviour and marketing $[6,12]$ and lead to a shifting from a focus in convenience and price to a deeper attention on quality $[6,13]$. Dog and cat owners have a tendency to spend more on premium feed among other unnecessary products [14] and they feel better when they spend more money to feed their pets.

Understanding in a deeper way the attitudes regarding nutrition of pet animals may improve communication with owners regarding nutrition. Furthermore is an integral part of eating behaviours of pet owners [2]. In fact, social and cultural factors that direct the pet owners' eating behaviours influence in the same way the feed selection and feeding practices for their pets [15].

The aim of the study was to profile which features are considered by owners as quality indicators when buying commercial pet foods.

\section{Results}

A total of 972 questionnaires were collected during the observation, of which 935 were actually used, after elimination of incomplete questionnaires.

In table 1 are reported the socio-demographic characteristics of surveyed pet owners' population. The surveyed population of pet food buyers was mainly composed by female owners. Most buyers were between 35 and 50 years old. The majority of the questionnaires were completed by workers, with a mediumhigh education. The majority of the population was resident in Centre and North of Italy, while the sample coverage for the South and Islands was lower. Participants were divided almost equally between those owning a dog, a cat, or both. 


\begin{tabular}{|c|c|}
\hline Characteristics & $\%$ and $n^{\circ}$ of valid responses \\
\hline Gender & $(n=935)$ \\
\hline Women & 61.8 \\
\hline Men & 38.2 \\
\hline Age & $(n=929)$ \\
\hline $18-34$ years & 31.5 \\
\hline $35-50$ years & 38.6 \\
\hline $51-64$ years & 22.1 \\
\hline$>64$ years & 7.8 \\
\hline Geographical area of residence & $(n=932)$ \\
\hline Nord West of Italy & 29.0 \\
\hline Nord East of Italy & 20.5 \\
\hline Center of Italy & 34.4 \\
\hline South Italy and islands & 16.1 \\
\hline Educational level & $(n=893)$ \\
\hline Primary / secondary school & 14.4 \\
\hline High school / professional qualification & 58.1 \\
\hline Degree / Specialization & 27.4 \\
\hline Occupation & $(n=931)$ \\
\hline Student & 15.7 \\
\hline Housekeeper & 8.8 \\
\hline Retired & 8.6 \\
\hline Worker & 61.5 \\
\hline Unemployed & 3.1 \\
\hline Other & 2.3 \\
\hline Animal owned (dogs and/or cats) & $(n=932)$ \\
\hline Dogs & 39.4 \\
\hline Cats & 30.8 \\
\hline Dogs and cats & 29.8 \\
\hline
\end{tabular}

Some questions were used to profile shopping habits of the participants (Table 2). The majority (65.3\%) of the sampled population bought both dry and wet pet food, while only about $10 \%$ purchased only wet food. The preferred marketing channel of the population was the pet store (63.3\%). About one-fourth (25.5\%) of consumers asked for veterinary advice before pet food purchasing, and almost one-third (30.4\%) relied on the information provided by major brands in their websites.

\begin{tabular}{|c|c|c|c|c|c|}
\hline $\begin{array}{l}\text { Pet food bought } \\
(\mathrm{n}=914)\end{array}$ & $\%$ & $\begin{array}{l}\text { Marketing channel for pet food } \\
(n=915)\end{array}$ & $\%$ & Source of nutritional advice for pet food $(n=931)$ & $\%$ \\
\hline Dry food & 24.7 & Supermarket & 15.8 & Friends and parents & 13.0 \\
\hline Wet food & 10.0 & Pet store & 63.3 & Online-blog & 9.8 \\
\hline \multirow[t]{4}{*}{ Dry \& wet pet food } & 65.3 & Online & 6.6 & Online-website & 30.4 \\
\hline & & More than one & 14.3 & Veterinary & 25.5 \\
\hline & & & & Other & 6.7 \\
\hline & & & & More than one & 14.7 \\
\hline
\end{tabular}


Table 3

reports the quality characteristics assessed on a 1-5 Likert scale score, the respective \%, and the resulting average score. The claim "Contains natural ingredients" received the highest score by consumers, while the high price resulted to be of lower importance for the consumers.

\begin{tabular}{|c|c|c|c|c|c|c|}
\hline \multirow[t]{2}{*}{ Characteristic } & \multicolumn{5}{|c|}{ Score (\% for each category) } & \multirow{2}{*}{$\begin{array}{l}\text { Average score } \\
(n=935)\end{array}$} \\
\hline & 1 & 2 & 3 & 4 & 5 & \\
\hline Presence of natural ingredient & 0.4 & 3.7 & 15.3 & 29.7 & 50.9 & 4.3 \\
\hline Clear production site & 0.9 & 3.8 & 16.8 & 31.0 & 47.5 & 4.2 \\
\hline Label clarity & 1.0 & 4.8 & 19.0 & 27.3 & 47.9 & 4.2 \\
\hline Be very appreciated by dog / cat & 0.3 & 2.7 & 18.5 & 32.5 & 46.0 & 4.2 \\
\hline Normal stool appearance & 0.7 & 2.8 & 18.8 & 33.4 & 44.3 & 4.2 \\
\hline Fresh meat presence & 1.5 & 6.0 & 21.5 & 27.1 & 43.9 & 4.1 \\
\hline Cruelty free & 3.3 & 6.9 & 23.1 & 22.6 & 44.1 & 4.0 \\
\hline Guarantee shiny coat & 1.0 & 5.0 & 22.7 & 35.5 & 35.8 & 4.0 \\
\hline Meat as first ingredient & 2.2 & 7.3 & 23.2 & 26.7 & 40.6 & 4.0 \\
\hline Food smell & 3.3 & 11.6 & 26.5 & 33.6 & 25.1 & 3.7 \\
\hline High protein content & 1.3 & 8.5 & 28.7 & 37.9 & 23.5 & 3.7 \\
\hline Food appearance & 4.3 & 10.8 & 29.0 & 31.5 & 24.4 & 3.6 \\
\hline Grain free & 6.0 & 19.4 & 32.2 & 24.6 & 17.8 & 3.3 \\
\hline Recyclable packaging & 13.9 & 18.3 & 24.5 & 22.0 & 21.3 & 3.2 \\
\hline Known brand & 12.0 & 20.3 & 28.8 & 25.3 & 13.5 & 3.1 \\
\hline Higher price than others & 24.1 & 27.6 & 26.9 & 13.7 & 7.7 & 2.5 \\
\hline \multicolumn{7}{|c|}{$\mathrm{n}=\mathrm{xx}$ : number of questionnaires effectively used for each question } \\
\hline
\end{tabular}

\section{Correlation analysis}

Correlation analysis showed that few correlations were relevant ( $<50 \%)($ Table 4$)$. Product site was linked with information on the label (clarity $\mathrm{R}=0.660$; use of natural ingredients $R=0.584$; cruelty-free products $R=0.564$ ). Carefulness to coat and stool appearance were linked each other $(R=0.579)$ and with the attention for pet preferences $(R=0.591$ and $R=0.529$ respectively). The attention to the brand was correlated with the attention to the price $(R=0.616)$. $A$ correlation between the carefulness to smell and food appearance was also observed $(R=0.761)$. 


\begin{tabular}{|c|c|c|c|c|c|c|c|c|c|c|c|c|}
\hline & Preference & Coat & Stool & $\begin{array}{l}\text { Food } \\
\text { smell }\end{array}$ & $\begin{array}{l}\text { Food } \\
\text { appearance }\end{array}$ & $\begin{array}{l}\text { Production } \\
\text { site }\end{array}$ & $\begin{array}{l}\text { Cruelty } \\
\text { free }\end{array}$ & $\begin{array}{l}\text { Clear } \\
\text { label }\end{array}$ & $\begin{array}{l}\text { Natural } \\
\text { ingredients }\end{array}$ & $\begin{array}{l}\text { Meat } \\
\text { first }\end{array}$ & $\begin{array}{l}\text { Fresh } \\
\text { meat }\end{array}$ & $\begin{array}{l}\text { Total } \\
\text { protein } \\
\%\end{array}$ \\
\hline Recyclable & 0.302 & 0.297 & 0.324 & 0.256 & 0.228 & 0.359 & 0.428 & 0.414 & 0.373 & 0.209 & 0.209 & 0.233 \\
\hline High price & $0.103 \mathrm{~ns}$ & 0.218 & $0.101 \mathrm{~ns}$ & 0.372 & 0.411 & 0.159 & 0.205 & 0.183 & 0.190 & 0.260 & $0.122 \mathrm{~ns}$ & 0.228 \\
\hline $\begin{array}{l}\text { Known } \\
\text { brand }\end{array}$ & 0.168 & 0.177 & $0.085 \mathrm{~ns}$ & 0.328 & 0.367 & $0.111 \mathrm{~ns}$ & $0.139 \mathrm{~ns}$ & 0.126 & 0.148 & 0.227 & 0.194 & 0.300 \\
\hline Grain free & 0.256 & 0.372 & 0.311 & 0.379 & 0.382 & 0.372 & 0.414 & 0.371 & 0.396 & 0.373 & 0.304 & 0.396 \\
\hline $\begin{array}{l}\text { High } \\
\text { protein \% }\end{array}$ & 0.211 & 0.205 & 0.249 & 0.181 & 0.247 & 0.331 & 0.175 & 0.326 & 0.345 & 0.402 & 0.511 & \\
\hline Fresh meat & 0.237 & 0.184 & 0.302 & 0.197 & 0.233 & 0.398 & 0.263 & 0.390 & 0.480 & 0.649 & & \\
\hline Meat first & 0.205 & 0.250 & 0.301 & 0.271 & 0.285 & 0.378 & 0.310 & 0.435 & 0.521 & & & \\
\hline $\begin{array}{l}\text { Natural } \\
\text { ingredients }\end{array}$ & 0.310 & 0.284 & 0.384 & 0.216 & 0.219 & 0.584 & 0.508 & 0.670 & & & & \\
\hline Clear label & 0.341 & 0.344 & 0.462 & 0.241 & 0.262 & 0.660 & 0.643 & & & & & \\
\hline Cruelty free & 0.361 & 0.396 & 0.459 & 0.339 & 0.352 & 0.564 & & & & & & \\
\hline $\begin{array}{l}\text { Production } \\
\text { site }\end{array}$ & 0.331 & 0.377 & 0.494 & 0.305 & 0.338 & & & & & & & \\
\hline $\begin{array}{l}\text { Food } \\
\text { appearance }\end{array}$ & 0.373 & 0.459 & 0.338 & 0.761 & & & & & & & & \\
\hline Food smell & 0.426 & 0.524 & 0.403 & & & & & & & & & \\
\hline Stool & 0.529 & 0.579 & & & & & & & & & & \\
\hline Coat & 0.591 & & & & & & & & & & & \\
\hline
\end{tabular}

ns: correlation not significant. Bold values are considered relevantly correlated $(>0.5)$.

\section{Multivariate correspondence analysis}

Multivariate correspondence analyses were performed in order to underline relevant associations between specific population segments and important factors in the decision-making process of pet food purchasing. The surveyed population was segmented according to the age, the educational level, the occupation, the geographical provenance, the type of food purchased and the animal owned (dog or cat).

Results of the segmentation for age classes are represented in Fig. 1. Older consumers ( $>65 \mathrm{y}$ ) gave low relevance with respect to the other population segments to the presence of recyclable packaging and the presence of the "cruelty-free" claim. Their attention was also poorly caught by some label information, such as its clarity, the site of production and the presence of natural ingredients. Also stool quality was poorly rated by elderly. On the other hand, younger owners (<35 y) put slightly more attention on stool appearance, on high percentage of proteins, and on the presence of recyclable packaging. Pet food appearance and smell were less relevant as well as pet acceptance. The cruelty free claim and the grain free claim were meanly more scored by the population aged 35 to 50 , who also rated slightly more the higher price.

Legends: Natur: presence of natural ingredient; Site: clear production site; Label: label clarity; Pref: be very appreciated by dog / cat; Stool: normal stool appearance; FreshMeat: fresh meat presence; CrueltyFree: cruelty free; Fur: guarantee shiny coat; Meat1: meat as first ingredient; Odour: food smell; TP\%: high protein content; Present: food appearance; GrainFree: grain free; Recyc: recyclable packaging; Brand: known brand; HighPrice: higher price than others. Age classes: $18-34$ y; $35-50$ y; 51-64 y; $>64$ y.

Results of the segmentation for education level are represented in Fig. 2. Pet owners with the higher educational level (degree/specialization) scored less pet food smell and appearance, high price and renowned brand, but they declared higher attention to stool and coat appearance. Positive decision factors for this population segment were label clarity, the site of production, the presence of natural ingredients, and grain-free and cruelty-free claims. Unlike graduate owners, the population having a primary educational level considered less relevant label information such as production site and percentage of proteins, as well as label clarity. For this population segment the presence of a cruelty free claim was not a decisional factor. A healthy stool and coat appearance were relevant for consumers with high school or professional qualification, together with the presence of recyclable packaging.

Legends: Natur: presence of natural ingredient; Site: clear production site; Label: label clarity; Pref: be very appreciated by dog / cat; Stool: normal stool appearance; FreshMeat: fresh meat presence; CrueltyFree: cruelty free; Fur: guarantee shiny coat; Meat1: meat as first ingredient; Odour: food smell; TP\%: high protein content; Present: food appearance; GrainFree: grain free; Recyc: recyclable packaging; Brand: known brand; HighPrice: higher price than others. HS: degree/specialization; MD: High school / professional qualification FS: Primary / secondary school

Housekeeper gave more attention to cruelty free claim and low cereal content. Less relevant for student was label clarity, food smell and appearance and pet preferences, as well as coat quality and stool appearance. Given that our findings were based on an unbalanced number of housekeepers and students 
respect to workers, the results from such analyses should therefore be treated with considerable caution.

Results from the segmentation according to macroscopic regions of the Italian peninsula are reported in Fig. 3 . It is relevant to notice that scores assigned in the South/insular regions were always higher than the rest of Italy, while lower scores were found in the North-West. The variability in the mean assigned score was about $50 \%$ more for the importance of the high price in the choice of pet food, given in the South with respect to the North-West.

Legends: Natur: presence of natural ingredient; Site: clear production site; Label: label clarity; Pref: be very appreciated by dog / cat; Stool: normal stool appearance; FreshMeat: fresh meat presence; CrueltyFree: cruelty free; Fur: guarantee shiny coat; Meat1: meat as first ingredient; Odour: food smell; TP\%: high protein content; Present: food appearance; GrainFree: grain free; Recyc: recyclable packaging; Brand: known brand; HighPrice: higher price than others. NO: North-West of Italy; NE: North-East of Italy; Center: Center of Italy; South: South of Italy and islands

The appearance, the smell, the higher cost and some label indication (high protein, meat as first ingredient, grain free) were more relevant for wet pet food buyers. Cat owners gave more importance to pet food appearance and smell, but less to recyclable packaging, while dog owners focused more on presence of meat as the first ingredient listed in the composition and on healthy stool appearance.

\section{Discussion}

Even if the survey was shared only in pet stores and fairs cutting off some market sectors of pet food (i.e. e-commerce) and limited the coverage for specific population segments (i.e. elder people), it was possible to highlights which characteristics were perceived as quality indicators by pet owners during pet food choosing process.

In this study, owners appeared to be divided between dogs, cats and both dogs and cats owners ( $36.9 \% ; 33.4 \% ; 29.7 \%$ respectively) with only a little prevalence of dog owners. This tendency was confirmed by the result of a national report [1], that reported an higher percentage of owned dogs (27.1\%) compared to cats $(18.3 \%)$ in the Italian family.

A higher percentage of female owners involved in pet nutrition compared to male was reported, confirming the trend found also in another study [16]. Our data reported an higher incidence of pet store (64.8\%) as a preferred shopping channel, but, for this result, our data can be considered partial because our survey was conducted in pet stores. In Assalco-Zoomark report [1], instead, it was reported that the major part of pet food in term of quantity was bought in supermarket (63.6\% considering hypermarket, supermarket and discount) and only around a quarter in pet stores (26.3\%).

In assessing quality, Italian pet food buyers considered the most important aspect the presence of natural ingredients (average score 4.3/5). This may reflect the nowadays trend present also in human nutrition in which there is an increasing attention on a more natural diet [17]. Pet food is becoming more "humanized" and it follows human food trends. The type of feeding used for pet might reflect the relationship between humans and animals and could be considered as a symbolic inclusion of the pet in the owner's family and reflects the pet owner's culture or ideology; furthermore, the owners in this way felt to take care of the health of their pet [15]. In a recent study considering relationship between children and household pets, the pet is considered as the child's playmate from the $70.7 \%$ of the interviewed families [18].

At the same time also the clear provenience of pet food (4.2/5) was an important factor, as well as the information wrote on label and their clarity (4.2/5). Correlation analysis too revealed a linkage between these two aspects.

Another actual trend in pet food industries was the development of grain free products. In fact, consumers showed some concern about quality and nutritional value of cereals and their actual utility for pets as well as possible origin of allergies [19]. However, from this preliminary survey, this characteristic seems not to be a major priority to the Italian consumer. The average score of this features was one of the lowest (3.3/5) as well as the presence of recyclable packaging $(3.2 / 5)$ and the known brand (3.1/5). Higher price compared to other similar products (2.5/5) was the less important parameter to evaluate pet food quality according to Italian buyers. The reason could be linked to a decreasing confidence in famous large companies for a part of consumers.

Considering this results, it was highlighted a big responsibility for veterinarians in influencing the pet owners on pet food choice. In fact, around a quarter of consumers (25.5\%) asked for advice in pet food choice to their veterinaries. Veterinarians should firstly be able to correctly evaluate pet food quality and should have a deep knowledge on animal nutrition. This topic should be part of their formation. At the same time, also pet food industry had a big role in provide the information to their buyer, in fact a third of consumers (30.4\%) put their trust on details provided from brand websites. Pet food companies should rely on experts in the field to edit the information on their websites. This result confirmed the findings of previous study [20] in which veterinarians were the most common source of information about pet nutrition.

In another study conducted in North America [2], the attitudes of owners towards pet food were investigated and it was shown that an higher part of owners ( $15.8 \%$ of dog owners and $16.9 \%$ of cat owners) used Internet and other media as their primary sources of information.

"Cruelty free" is another aspect to take into consideration, even if there are still some concerns on its definition. It seemed to be perceived as highly important from the Italian consumer (4.0/5). The claim could be important also from a marketing point of view, being it an aspect focused from media and public opinion. However, nowadays it is not regulated by specific legislation. A possible perspective for Italian and European legislation could then be to improve the regulation on this topic.

Other concerns are linked with the clarity of the label that resulted as one of the most important factors for consumers (4.2/5). It is not easy to evaluate the quality of a pet food product only from the label and according to our knowledge, no studies evaluated what it is intended for label clarity from a consumer's point of view; further work should be needed. However, it is a quite important point since Reg. (EC) No 767/2009 on the placing on the market and use of feed 
clearly states that the feed label shall not mislead the user, as also FEDIAF (European Pet Food Industry Federation) underline with the development of the Code of Good Labelling Practice [21].

There was a distinction in two big categories of owners considering the correlation analysis. Consumers that charge for a high score for pet preference seemed to pay attention also to the coat and stool appearance, putting the attention generally more directly on pet wellness. On the other hand, people interested in known brands seem to pay attention also to the price and exterior characteristic of the feeds (such as the appearance and the smell), more than directly to pet.

This study revealed also a difference on quality perceived considering the age of consumers. For example, elder consumers tended to not consider the presence of recyclable packaging, which was instead interesting for the younger ones, maybe index of a major awareness of environmental impact. Furthermore, for elder consumers the mayor importance was on the high price, without considering the label information; on the contrary, younger consumers were interested more on information written on the label. Also in the evaluation of quality perceived for human food was reported an influence of age [22]. Educational level seemed to have an influence on pet food quality perception too and it was also reported in a study on human food habits that differences in educational level of mothers were linked to differences in eating habits of their children (i.e. consumption of soft drinks, sweets, fruit and vegetables) [23].

Considering the species of animal owned, it seemed that cat owners were more interested in how the pet food appeared externally. This could be linked to the fact that cats are notoriously fussy and owners know that a certain kind of feed can be eaten or not by their pet basing on its smell and appearance (i.e. texture). Dog owners, instead, focused more on the composition of the feed and in particular on the quantity of protein, maybe because of the new trend of considering the dog as a wolf. Also healthy stool appearance was important for them. In fact dog tend to have problem on stool consistency, especially large breeds [24]. However, further information on the size of the dog should be necessary in order to understand if there was a correlation with attention to stool consistency.

\section{Conclusion}

In conclusion, Italian pet food buyers considered as the most important quality indicator the presence of natural ingredients, while the least important aspect was the high price.. Furthermore, our results highlighted that consumers asked for advice on pet food in an equal proportion (about $30 \%$ ) to veterinary and websites of major brands. Information from this Italian survey can help pet food companies to profile communication strategies tailored for specific consumer segments. Data may be helpful to identify factors that influence the perceived quality of the purchased products for both dogs and cats owners.

\section{Methods}

The present survey was designed to investigate relevant habits and attitudes of dogs' and cats' owners in choosing and purchasing pet foods.

No approval by an institutional review board was required, because enrollment was on a voluntary basis, and the participants consented to anonymous information collection. In addition, questionnaires were blinded before statistical analysis, which was performed independently by a specialist on a synthetic database.

\section{Respondents}

The survey was designed and administered by trained staff in different pet stores and during sector fairs in Italy, during 9 months, from March to November 2018. The sample was represented by 935 statistical units from the section of dog and/or cat owners' population in charge of pet food purchase. The questionnaire was piloted among 100 persons before the survey.

\section{Structure of the questionnaire}

The questions selected for the survey were based on the existing literature, and in particular on Mascarello et al. [22]. Each question was developed with the assistance of experts (veterinarian, nutritionist, marketing research specialist) to gather information from owners about the target topics.

Ten questions in Italian language, divided into two sections, were included in the survey. The first section, containing 9 multiple choice questions, was designed to profile the population sample. Demographic variables included in the profiling were gender, age, geographical area, education and occupation. Other variables were included to profile consumers in terms of pet food purchasing attitudes (owned animal, preferred marketing channel, type of purchased pet food, sources of pet nutrition information).

In the second part, pet owners were asked to score from 1 to 5 ( $1=$ not important at all, $2=$ not very important, $3=$ quite important, $4=$ very important, $5=$ fundamental) the relevance of sixteen specific quality-associated characteristics in the decision-making process of pet food choice. The surveyed characteristics included pet preferences, coat and stool appearance, food smell and presentation, label information, controlled origin, ingredients, brand, price, recyclable packaging, cruelty free claim.

\section{Statistical analyses}

Data generated in this way were submitted to exploratory, correlation, and correspondence analysis. Exploratory analysis provided a description of the sample interviewed through frequency analysis, the use of synthetic indicators (median, mean, coefficient of variation), and the cross tabulation of specific variables so as to identify the main differences amongst the consumer groups. Correlation analyses were carried out by Bonferroni's corrected Spearman Rho, in order to highlight highly or poorly connected features. A strong correlation was detected when $> \pm 0.5$, a weak correlation when $< \pm 0.2$. Finally, profiling of the respondents according to interesting clusters (age, education, occupation, geographical origin, type of pet food, dog and/or cat ownership) was achieved by

Page $7 / 11$ 
using a multivariate Correspondence Analysis approach between scores and specific population segments. To this aim, data were first converted to Dummy variables, then grouped into specific Burt's table (one table for each target profiling feature) that were subsequently used for multivariate correspondence analysis. When a specific preference class was poorly represented (less than 10 cases), the cases were assigned to the adjacent preference class. The relative weight of each class of preference was standardized by considering its percentage occurrence in each specific population segment. All analyses were performed by using PAST version 2.3 (Hammer, Ø., Harper, D.A.T., Ryan, P.D. 2001. PAST: Paleontological statistics software package for education and data analysis. Palaeontologia Electronica 4(1): 9 pp).

\section{Declarations}

\section{Ethics approval and consent to participate}

No ethics approval process either within national or EU legal systems was needed for the present procedure, as enrolment in the survey was on a voluntary basis, and the participants consented verbally to anonymous information collection as per Regulation of the European parliament and of the council of 27 April 2016 (UE 2016/679). Data were collected directly from owners that were directly contacted by personal of front desk in the pet-shop that were able to explain the aim of questioner and to collect the consent. Interviewees agreed to participate in the study voluntarily by self-enrolling. They were informed that their answers would be published in a study. No animals were involved in the study.

\section{Consent for publication}

The participants consented to anonymous information collection as per Italian Data Protection Code - Legislative Decree no. 196/2003. Interviewees agreed to participate in the study voluntarily by self-enrolling. They were informed that their answers would be published in a study.

\section{Availability of data and materials}

The datasets analysed during this study are available from the corresponding author on reasonable request.

\section{Competing interests}

The authors declare that they have no competing interests.

\section{Funding}

This research was funded by Natural Line SRL, Via Mazzini 26, 54027 Pontremoli (MS) Italy (funding 2018: SCHA_CT_RIC_18_02). The funding body approved the proposed study design, data collection and analysis.

\section{Authors' contributions}

MV: data collection, support data analysis and preparation of manuscript. DV: data collection, support data analysis and preparation of manuscript EV: coordination and preparation of manuscript MG: data management and data analysis JN: data management, planning of the study. LP: data management, planning of the study. DB: data management, planning of the study. AS: coordination role. All authors read and approved the final manuscript.

\section{Acknowledgements}

We thank Natural Line SRL, Via Mazzini 26, 54027 Pontremoli (MS) Italy for funding the research.

\section{References}

1. Assalco-Zoomark. Alimentazione e cura degli animali da compagnia. 2019.

2. Michel KE, Willoughby KN, Abood SK, Fascetti AJ, Fleeman LM, Freeman LM, et al. Attitudes of Owners Towards Pet Foods. 2008;233:1-5.

3. Suarez L, Peña C, Carretón E, Juste MC, Bautista-Castaño I, Montoya-Alonso JA. Preferences of owners of overweight dogs when buying commercial pet food. J Anim Physiol Anim Nutr (Berl). 2012;96:663-7. doi:10.1111/j.1439-0396.2011.01193.x.

4. Contreras S. The Dog Food Project - Ingredients to avoid. 2007. 2007. http://www.dogfoodproject.com/index.php?page=badingredients. Accessed 28 May 2019.

5. Bohrer T. Pet Food Packaging: Evolution, Revolution \& Innovation - Paper, Film \&amp; Foil Converter. 19/08/2011. 2011. https://www.pffconline.com/flexpack/9770-pet-food-evolution-0819. Accessed 28 May 2019. 
6. Boya UO, Dotson MJ, Hyatt EM. A comparison of dog food choice criteria across dog owner segments: an exploratory study. Int J Consum Stud. 2015;39:74-82. doi:10.1111/ijcs.12145.

7. Kraft W. Geriatrics in canine and feline internal medicine. Eur J Med Res. 1998;3:31-41. http://www.ncbi.nlm.nih.gov/pubmed/9512965. Accessed 3 Oct 2019.

8. Handl S. The Barf Trend Advantages, Drawbacks and Risks. Vet Focus. 2014;24:16-23. https://www.scribd.com/document/381885688/Articulo-deRoyal-Canin-The-Barf-Trend-Advantages-Drawbacks-and-Risks. Accessed 17 May 2019.

9. van Bree FPJ, Bokken GCAM, Mineur R, Franssen F, Opsteegh M, van der Giessen JWB, et al. Zoonotic bacteria and parasites found in raw meat-based diets for cats and dogs. Vet Rec. 2018;182:50. doi:10.1136/vr.104535.

10. Waters A. Raw diets: are we at a turning point? Vet Rec. 2017;181:384.2-384. doi:10.1136/vr.j4709.

11. Freeman LM, Chandler ML, Hamper B a. Timely Topics in Nutrition of raw meat - based diets for dogs and cats. Javma. 2013;243:1549-58.

12. Boya UO, Dotson MJ, Hyatt EM. Dimensions of the dog-human relationship: A segmentation approach. J Targeting, Meas Anal Mark. 2012;20:133-43. doi:10.1057/jt.2012.8.

13. Pask E, Scott L. Feeding Fido: How to really read a dog food label. 2012. 2012. https://moderndogmagazine.com/articles/feeding-fido/4870. Accessed 28 May 2019.

14. Landes L. Pet Ownership: A Financial and Emotional Responsibility • Consumerism Commentary. 20/06/2018. 2010. https://www.consumerismcommentary.com/pet-ownership-a-financial-and-emotional-responsibility/. Accessed 28 May 2019.

15. Michel KE. Unconventional Diets for Dogs and Cats. Vet Clin North Am - Small Anim Pract. 2006;36:1269-81.

16. Morelli G, Bastianello S, Catellani P, Ricci R. Raw meat-based diets for dogs: survey of owners' motivations, attitudes and practices. BMC Vet Res. 2019;15:74. doi:10.1186/s12917-019-1824-x.

17. Nie C, Zepeda L. Lifestyle segmentation of US food shoppers to examine organic and local food consumption. Appetite. 2011;57:28-37. doi:10.1016/j.appet.2011.03.012.

18. Russo N, Vergnano D, Bergero D, Prola L. Small pilot survey on parents' perception of the relationship between children and pets. Vet Sci. 2017;4:1-5.

19. Laflamme D, Izquierdo O, Eirmann L, Binder S. Myths and misperceptions about ingredients used in commercial pet foods. Vet Clin North Am Small Anim Pract. 2014;44:689-98, v. doi:10.1016/j.cvsm.2014.03.002.

20. Laflamme DP, Abood SK, Fascetti AJ, Fleeman LM, Freeman LM, Michel KE, et al. Pet feeding practices of dog and cat owners in the United States and Australia. J Am Vet Med Assoc. 2008;232:687-94. doi:10.2460/javma.232.5.687.

21. European Pet Food Industry Federation (FEDIAF). Code of Good Labelling Practice for Pet Food. 2011; October:1-63.

22. Mascarello G, Pinto A, Parise N, Crovato S, Ravarotto L. The perception of food quality. Profiling Italian consumers. Appetite. 2015;89:175-82. doi:10.1016/j.appet.2015.02.014.

23. Vereecken CA, Keukelier E, Maes L. Influence of mother's educational level on food parenting practices and food habits of young children. Appetite. 2004;43:93-103. doi:10.1016/J.APPET.2004.04.002.

24. Hernot DC, Biourge VC, Martin LJ, Dumon HJ, Nguyen PG. Relationship between total transit time and faecal quality in adult dogs differing in body size. J Anim Physiol Anim Nutr (Berl). 2005;89:189-93. doi:10.1111/j.1439-0396.2005.00544.x.

\section{Figures}


Figure 1: Results of the segmentation for age classes.

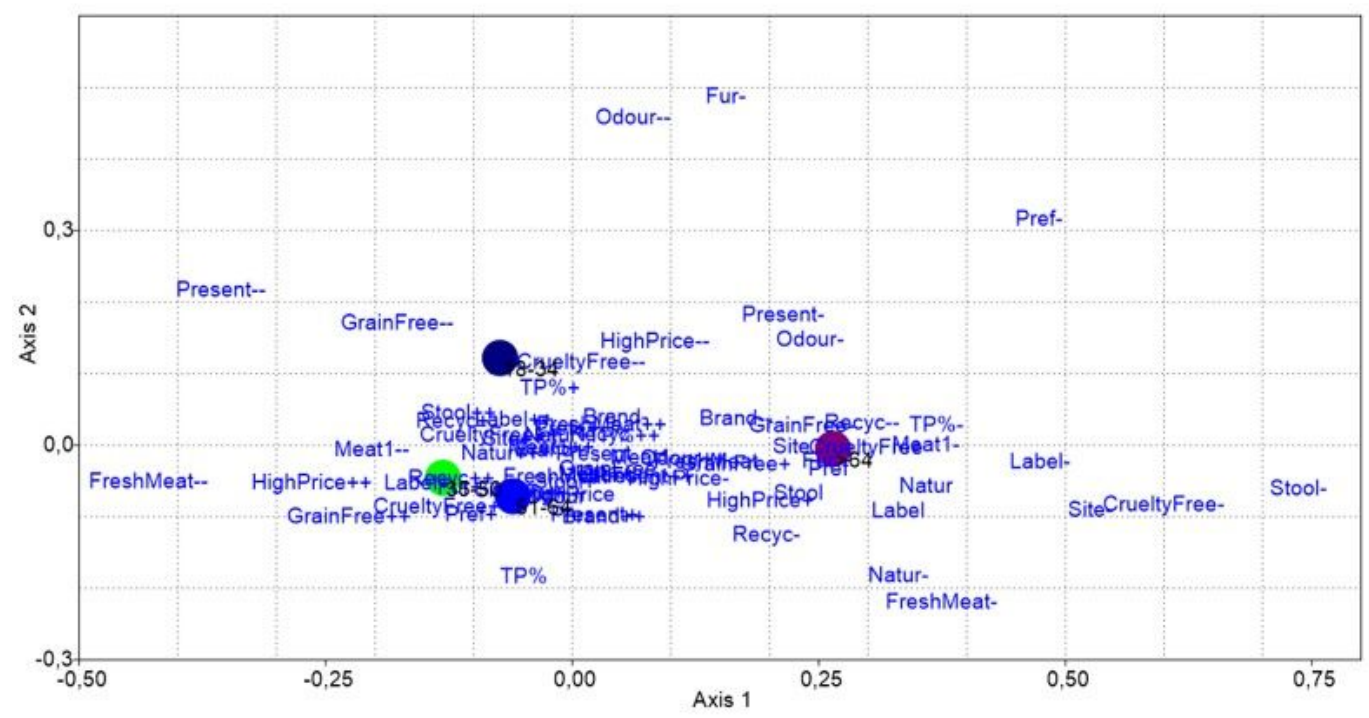

\section{Figure 1}

Results of the segmentation for age classes.

Figure 2: Results of the segmentation for educational level.

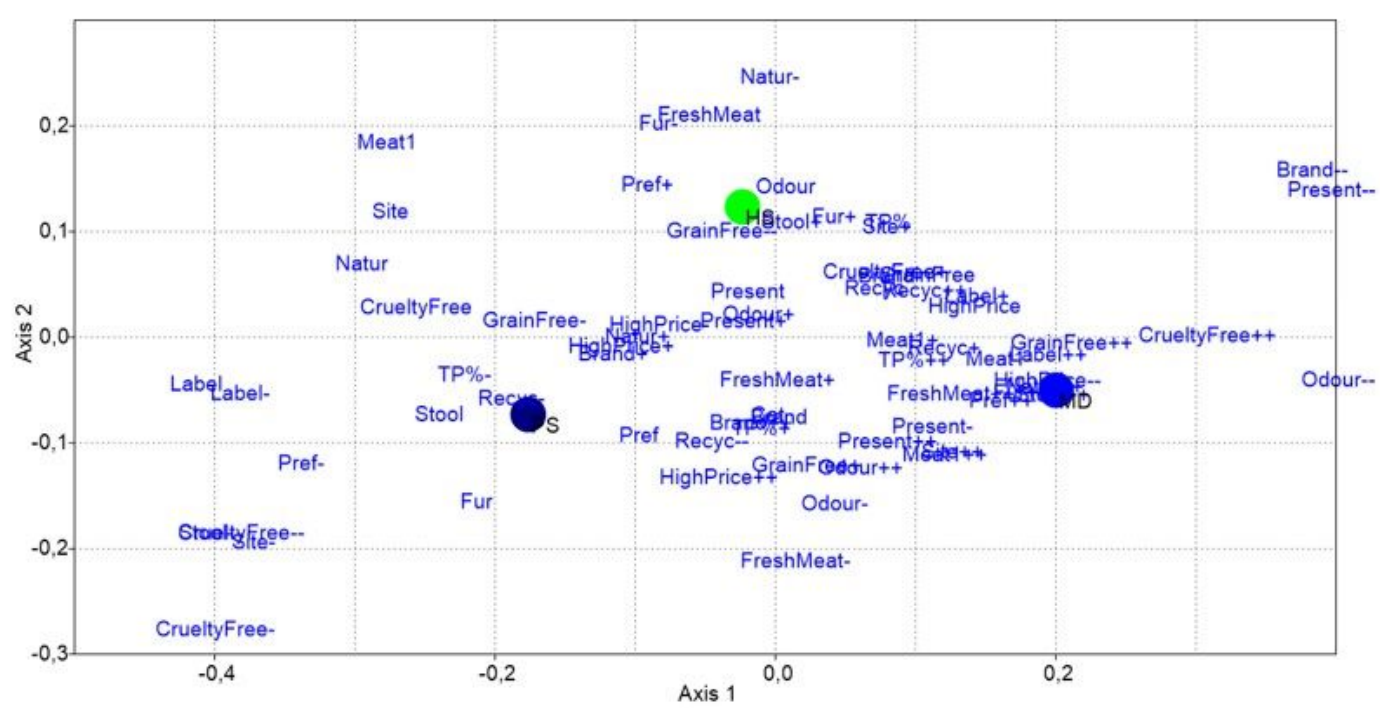

Figure 2

Results of the segmentation for educational level. 


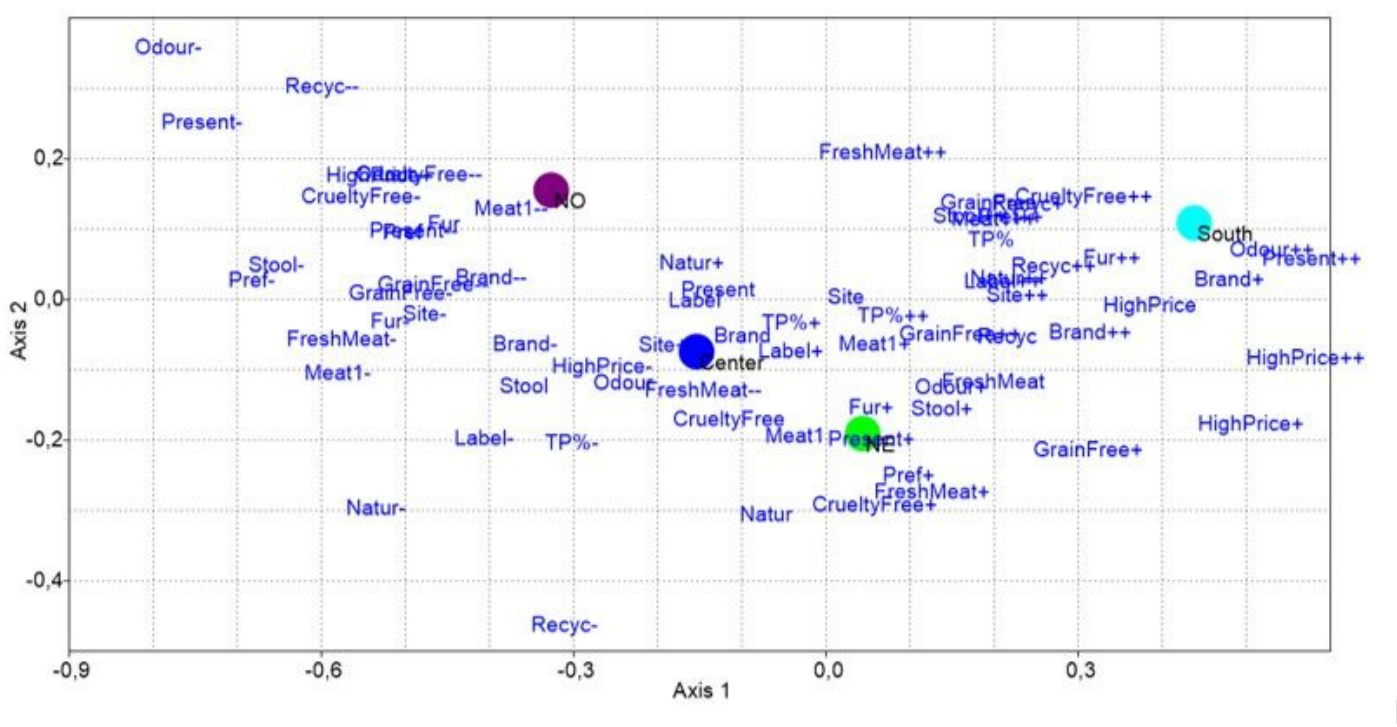

Figure 3

Results from the segmentation according to macroscopic regions of the Italian peninsula. 